\title{
DECLÍNIO EM PEQUENAS EMPRESAS: ABORDAGENS E TRABALHOS RELEVANTES ${ }^{1}$
}

\author{
Luiz Antonio de Camargo Guerrazzi ${ }^{2}$ \\ Fernando Antonio Ribeiro Serra ${ }^{3}$
}

http://dx.doi.org/10.1590/1413-2311.176.66629

\begin{abstract}
RESUMO
As pequenas empresas por seu relevante papel socioeconômico têm despertado crescente interesse da academia. Altas taxas de mortalidade associados às pequenas empresas têm sido objeto de pesquisas que investigam causas e fatores desencadeadores do declínio organizacional, fenômeno que antecede à morte da empresa. Neste artigo foi realizado um estudo bibliométrico em nove periódicos líderes na pesquisa em pequenas empresas, para obter uma visão geral e estrutural do conhecimento acumulado. Foi obtida uma amostra de 449 artigos relacionados ao declínio publicados entre 1989 e 2014. O método empregado permitiu a análise dos autores mais prolíficos, citações e obras com maior impacto, cocitações para entender a estrutura intelectual do campo e temas pesquisados para entender o foco da pesquisa. Foram empregadas técnicas de análise multivariada de dados como a análise fatorial exploratória e o escalonamento multidimensional (MDS). Foram identificados quatro principais temas pesquisados entrelaçando causas internas e externas como causadoras do declínio: empreendedorismo; administração estratégica e desempenho; inovação e evolução; liabilities (ameaças) e ambiente. Este estudo indica que o declínio é desencadeado pela interação de causas internas e externas às empresas, fazendo um contraponto às pesquisas existentes que abordam ora umas ora outras e não estabelecem uma relação entre elas. Contribui para a academia com as bases sobre as quais novas pesquisas podem ser desenvolvidas e para a prática gerencial uma vez que identifica as causas do declínio e possibilita a tomada de decisões para neutralizá-las.
\end{abstract}

Palavras-Chave: Pequena Empresa. Declínio Organizacional. Estratégia. Liability of Newness. Bibliometria.

\section{DECLINE IN SMALL BUSINESSES: APPROACHES AND SIGNIFICANT WORK}

\author{
ABSTRACT \\ ${ }^{1}$ Recebido em 01/08/2016; aprovado em 18/07/2017. \\ ${ }^{2}$ Universidade Nove de Julho - luizguerrazzi@ hotmail.com. \\ ${ }^{3}$ Universidade Nove de Julho - fernando.antonio.ribeiro.serra@ gmail.com.


Small businesses for their socio-economic relevance have aroused growing interest from academia. High mortality rates associated with small businesses have been the subject of research delving causes and triggering factors of organizational decline, a phenomenon that precedes the death of the company. In this article it was performed a bibliometric study in nine top ranked journals in research over small businesses to get a general and structural view of the accumulated knowledge. It was obtained a sample of 449 articles related to the decline published between 1989 and 2014. The method allows the analysis of the most prolific authors, citations and work with greater impact, co-citations to understand the intellectual structure of the field and researched topics to understand the focus of search. Multivariate data analysis techniques were employed as exploratory factor analysis and multidimensional scaling (MDS). It was identified four main themes interweaving internal and external factors as the causes of the decline: entrepreneurship; strategic management and performance; innovation and evolution; liabilities (threats) and the environment. This study indicates that the decline is triggered by the interaction of internal and external causes to companies, making a counterpoint to existing research addressing that does not establish a relationship between them. It contributes to the academia with the basis on which new research can be developed and to management practice since identifies the causes of the decline and enables decision making to neutralize them.

Keywords: Small Business. Organizational Decline. Strategy. Liability of Newness. Bibliometric.

\section{DESCENSO EM PEQUENAS EMPRESAS: ENFOQUES Y TRABAJOS SIGNIFICATIVOS}

\section{RESUMEN}

Las pequeñas empresas, por su significativo papel socioeconómico han han atraído creciente interés del mundo académico. Las altas tasas de mortalidad asociadas a las pequeñas empresas han sido objeto de estudios de investigación de las causas y los factores de deterioro de la organización, un fenómeno que precede a la muerte de la empresa. En este artículo se realizó un estudio bibliométrico en nueve revistas líderes en la investigación en las pequeñas empresas para obtener una visión general y estructural del conocimiento acumulado. Se obtuvo una muestra de 449 artículos relacionados con la disminución publicados entre 1989 y 2014. El método permite el análisis de los autores más prolíficos, citas bibliográficas y trabajar con mayor impacto, cocitas para entender la estructura intelectual del campo e investigó temas para comprender el enfoque de investigación. Las técnicas de análisis de datos multivariados fueron empleados como el análisis factorial exploratorio y escalamiento multidimensional (MDS). Se identificaron cuatro temas principales que se entrelazan factores internos y externos como la causa de la decadencia: el espíritu empresarial; la gestión y el desempeño estratégico; la innovación y la evolución; liabilities (amenazas) y el medio ambiente. Este estudio indica que la disminución es provocada por la interacción de causas internas y externas a las empresas, haciendo un contrapunto a las investigaciones realizadas que no establecen una relación entre ellos. Contribuye a la academia con la base sobre la cual se puede desarrollar nuevas investigaciones y con las prácticas de gestión por identificar las causas de la decadencia y permite la tomada de decisiones para neutralizarlos. 
Palabras-Clave: Pequeña Empresa. Declive de la Organización. Estrategia. Liabilities of Newness, Bibliometría.

\section{INTRODUÇÃO}

O interesse por declínio organizacional e fracasso de empresas consideradas de sucesso tem crescido para autores que se dedicam a publicar para executivos (ver COLLINS, 2009; DAMODARAN, 2011; HAMEL, 2012). O mesmo aconteceu na pesquisa acadêmica a partir do artigo seminal de Whetten (1980) que, estimulado pelos resultados adversos das empresas americanas ao competir com as japonesas, chamou atenção dos pesquisadores para a importância do tema e do seu estudo. O declínio ocorre quando há influência negativa no desempenho da empresa a partir da deterioração de sua base de recursos por determinado período de tempo (BRUTON; OVIATT; WHITE, 1994; CAMERON; WHETTEN; KIM, 1987; WEITZEL; JONSSON, 1989), que conforme sugerem alguns autores, em pelo menos é de três anos (LUSSIER; PFEIFER, 2001; MORENO; CASILLAS, 2008).

A pesquisa sobre o tema tem se desenvolvido com o intuito de entender como empresas entram em declínio, considerando-o como uma etapa do ciclo de vida de empresas maduras, mas que devido a perturbações em processos variados, pode ocorrer igualmente em qualquer outro estágio da vida (CAMERON; WHETTEN; KIM, 1987). Pesquisas apresentam fatores externos e internos como iniciadores do declínio. Estudos mostram que os primeiros anos de atividade duma nova e pequena empresa são os mais difíceis. Dentre os fatores que influenciam as taxas de mortalidade nos primeiros anos estão: falta de legitimidade (SINGH; TUCKER; HOUSE, 1986; STINCHCOMBE, 1965); falta de recursos (HOLTZ-EAKIN; JOULFAIAN; ROSEN, 1994) e excesso de confiança dos sócios-fundadores (TOWNSEND; BUSENITZ; ARTHURS, 2010) causando uma espécie de miopia gerencial que impede que os primeiros sintomas do declínio sejam percebidos (WITZEL; JONSSON, 1989). São citados também fatores externos, tais como desconhecimento de características da indústria e do ambiente (AUDRETSCH, 1991).

As pequenas empresas são mais vulneráveis, principalmente nos primeiros anos de vida. Têm um importante papel socioeconômico, portanto a compreensão das causas que as levam ao declínio é amplamente justificada. As pequenas empresas têm grande representatividade no cenário, sendo responsáveis por 52\% dos empregos formais e participando com $27 \%$ do PIB no Brasil (Sebrae, 2014). Na Europa, geram dois terços dos empregos (FRANCO; HAASE, 2010) e 
nos Estados Unidos 70\% dos empregos (US - Small Business Administration, 2014). A alta taxa de mortalidade é outra característica comum. No Brasil, 48\% desaparecem após cinco anos de fundação (IBGE, 2010) e na Europa, 66\% após seis anos (TIMMONS, 1994).

Os objetivos deste artigo foram: identificar os trabalhos e os autores mais influentes e de como variou sua influência relativa no período pesquisado; revelar a estrutura intelectual da pesquisa existente, isto é, como trabalhos e autores se inter-relacionam e as principais vertentes com as quais o tema é abordado utilizando técnicas da bibliometria como a análise de citações, cocitações e a análise fatorial exploratória.

Para alcançar os objetivos procedeu-se esta pesquisa bibliométrica em periódicos de administração com alto fator de impacto. São eles: Journal of Small Business Management (JSBM), Journal of Business Venturing (JBV), Entrepreneurship Theory and Practice (ETP), Strategic Entrepreneurship Journal (SEJ), Journal of Product Innovation Management (JPIM), Family Business Review (FBR), Small Business Economics (SBE), International Small Business Journal (ISBJ) e Entrepreneurship \& Regional Development (ERD).

Pelo fato de ser uma revisão de literatura, este estudo contribuiu no entendimento do conhecimento acumulado sobre declínio organizacional, estabelecendo caminhos pelas quais novas pesquisas podem ser conduzidas. A principal contribuição deste trabalho reside na conclusão de que fatores de origem externa, entendidos sob a perspectiva da ecologia organizacional e da competitividade (organização industrial de Porter) e de origem interna, estudados sob o foco da teoria da decisão (alto escalão) e da teoria baseada em recursos, interagem, acionando o gatilho do declínio. Deste modo, o trabalho complementa outros estudos relacionados ao tema, como Gaskill, Auken e Manning (1993) e Franco e Haase (2010) que pesquisaram sobre causas de fracasso em pequenas empresas junto aos proprietários e Serra, Ferreira e Almeida (2013) que estudaram, em uma pesquisa bibliométrica, a evolução de pesquisas em declínio. O estudo também contribuiu para a compreensão de causas e antecedentes do declínio, importante para a prática da gestão.

O trabalho compõe-se de cinco partes. Na primeira será apresentado o referencial teórico sobre a pesquisa em declínio organizacional tradicional. Na sequência, serão discutidos o método de coleta de dados e os procedimentos utilizados para a análise bibliométrica. A seguir os resultados da pesquisa e a discussão subsequente, apontando os subcampos de estudo no tema. Na última seção, com as considerações finais, limitações e propostas para pesquisas futuras, a 
pesquisa é concluída.

\section{REVISÃO DA LITERATURA}

Os autores que têm se dedicado à revisão dos estudos sobre declínio organizacional, argumentam que a pesquisa é fragmentada (TRAHMS et al., 2013) e, embora possua um volume de estudos crescente, ainda existem lacunas importantes a serem estudadas (SERRA et al., 2013). Mesmo que os trabalhos passados tenham se dedicado principalmente às empresas maduras, é importante conhecer o conteúdo fundamental dos estudos com o intuito de estruturar a pesquisa para empresas de pequeno porte. Estes estudos sobre declínio organizacional buscam compreender porque algumas empresas passam por dificuldades e não conseguem sobreviver às forças do mercado e passam pela deterioração dos recursos, redução da dimensão e queda no desempenho (WHETTEN, 1987).

$\mathrm{Na}$ busca pelas respostas, os estudiosos em declínio organizacional se utilizaram de diversas abordagens teóricas, dentre elas se destacam: ecologia organizacional (ALDRICH, 1979; FREEMAN; CARROLL; HANNAN, 1983; HANNAN; FREEMAN, 1977, 1984, 1989; TUSHMAN; ROMANELLI, 1985; ALDRICH; AUSTER, 1986; HANNAN; CARROLL, 1992); estrutura social (STINCHCOMBE, 1965; TUMA; HANNAN, 1984); estrutura industrial (PORTER, 1980; 1985); aprendizagem e tomada de decisão ( CYERT; MARCH, 1963; KAHNEMAN; TVERSKY, 1979; STAW; SANDELANDS; DUTTON, 1981; HAMBRICK; MASON, 1984; LEVITT; MARCH, 1988; CHILD, 1992) e recursos (PENROSE, 1959; BARNEY, 1991).

O declínio organizacional nas empresas de pequeno porte é explicado sob várias perspectivas. Visões internas e externas à empresa são investigadas e características associadas à sua fragilidade são citadas como gatilhos para o processo.

Empresas de pequeno porte correm risco de fracassar desde períodos imediatamente pósfundação, seja por problemas de inexperiência de seus fundadores, ou por falta de reconhecimento por parte de fornecedores ou competidores (STINCHCOMBE, 1965; ALDRICH; AUSTER, 1986; GASKILL, AUKEN; MANNING, 1993; FRANCO; HAASE, 2010). O despreparo dos gestores leva ao não aproveitamento eficiente dos recursos disponíveis, à baixa proteção de vantagens competitivas e à falta de visão para prospecção de novos recursos 
(MARCH, 1990; BARNEY, 1991).

Aspectos cognitivos também devem ser considerados. A criação de uma pequena empresa é cercada de incertezas e riscos que os proprietários assumem, mas que nem sempre, estão preparados para enfrentá-los. Crises econômicas, alterações no ambiente competitivo e surgimento de novos processos demandam uma aprendizagem eficiente que possa levar a uma rápida adaptação, pois de outro modo podem levar ao declínio e extinção da empresa (KLOTZ; HMIELESKI; BRADLEY; BUSENITZ, 2014; STAW et al., 1981; PORTER, 1980; TUMA; HANNAN, 1984). A experiência prévia de outros insucessos levam à maior longevidade em novas empresas, seja pelo aprendizado obtido, seja pela redução do nível de autoconfiança que, de acordo com a teoria da hubris, é uma causa conhecida de fracasso empresarial (HAYWARD; SHEPHERD; GRIFFIN, 2006; TOWNSEND et al., 2010).

Na ecologia organizacional, o declínio é visto como sintomático aos baixos níveis de inércia estrutural, comum em empresas jovens e de menor porte. Alguns autores argumentam que os processos de seleção tendem a favorecer organizações cujas estruturas são difíceis de alterar, ou seja, altos níveis de inércia. As empresas que se tornam incompatíveis com o ambiente são substituídas por intermédio da competição por novas organizações mais adequadas às demandas externas (FREEMAN et al., 1983; HANNAN; FREEMAN, 1977). Vale ressaltar que o estudo de ecologia organizacional não foca nos aspectos internos específicos e contextuais da empresa, mas sim no estudo das populações de empresas.

\section{MÉTODO}

\subsection{PROCEDIMENTOS DA COLETA DE DADOS}

Foram selecionados os principais periódicos de administração voltados a pequenas empresas com fator de impacto superior a 1,4 (avaliação Capes - Qualis A1) publicado no Journal Citation Reports, no portal ISI - Web of Knowledge, exceto o Journal of Small Business Management cujo fator de impacto é de 1,353 , mas mantido na seleção por ser um periódico especializado no tema da pesquisa (Tabela 1). 
Tabela 1 - Artigos de declínio em pequenas empresas

\begin{tabular}{|c|c|c|c|c|c|}
\hline Periódico & $\begin{array}{c}\text { Fator de } \\
\text { impacto - } 2014\end{array}$ & $\begin{array}{c}\text { Primeiro ano } \\
\text { na ISI }\end{array}$ & $\begin{array}{c}\text { Artigos } \\
\text { disponíveis - } \\
\text { ISI }\end{array}$ & $\begin{array}{c}\text { Artigos } \\
\text { validados }\end{array}$ & $\%$ \\
\hline JSBM & 1,353 & 1995 & 658 & 55 & 8,4 \\
\hline JBV & 3,678 & 1987 & 958 & 98 & 10,2 \\
\hline ETP & 3,144 & 2003 & 594 & 41 & 6,9 \\
\hline SEJ & 2,000 & 2007 & 181 & 18 & 9,9 \\
\hline JPIM & 1,696 & 1984 & 1751 & 0 & 0,0 \\
\hline FBR & 5,528 & 2005 & 278 & 18 & 6,5 \\
\hline SBE & 1,795 & 1992 & 1336 & 164 & 12,3 \\
\hline ISBJ & 1,800 & 2003 & 585 & 30 & 5,1 \\
\hline ERD & 1,519 & 2001 & 409 & 25 & 6,1 \\
\hline Total & & & 6750 & 449 & 6,7 \\
\hline
\end{tabular}

Fonte: ISI - Web of Knowledge.

\subsection{PROCEDIMENTOS DE SELEÇÃO DA AMOSTRA}

A próxima etapa para a definição dos artigos consistiu em pesquisar, dentre os selecionados, aqueles relacionados a declínio. Para isso foi utilizado um conjunto de palavraschave definidas por Serra, Ferreira, e Almeida (2013) no campo "topic” da ferramenta de busca. As palavras utilizadas foram: decline, decay, bankrupticy, failure, turnaround, retrenchment, longevity e life-cyle, os autores incluiram a palavra mortality, termo associado ao fracasso de pequenas empresas. Finalmente foi feita uma triagem pela leitura dos resumos, eliminando-se os artigos não relacionados com o tema, resultando numa amostra com 449 artigos (Tabela 1).

\subsection{PROCEDIMENTOS DE ANÁLISE}

Nesta pesquisa bibliométrica foram conduzidas as análises de citação, cocitação e análise 
fatorial exploratória em conjunto com escalonamento multidimensional (MDS) para classificação e ordenação das referências usadas na amostra. A análise de citação é baseada na contagem de vezes com a qual um trabalho é citado por outros pesquisadores. Pressupõe-se que autores citem trabalhos que sejam relevantes para sua própria pesquisa e, portanto, os mais citados têm maior influência no tema pesquisado (CULMAN; O'REILLY; CHATMAN, 1990). Análise de cocitação é usada para entender a estrutura intelectual de um tema (RAMOS-RODRÍGUEZ; RUÍZ-NAVARRO, 2004; SUBRAMANYAM, 1983; WHITE; MCCAIN, 1998). Cocitação é uma forma de pareamento de documentos que mede a frequência com que um par de artigos é citado conjuntamente.

Para a análise fatorial foi utilizado o método da rotação varimax (ACEDO; BARROSO; GALAN, 2006; LIN; CHENG, 2010) com auxílio do software SPSS, versão 20. Foi utilizada a rotação varimax, pois seus resultados são mais facilmente interpretáveis e porque forçam os vetores de resultado, representados pelos fatores para a menor correlação entre eles (FABRIGAR; WEGENER; MACCALLUN, 1999). A análise fatorial agrupa as referências bibliográficas com base em sua proximidade temática ou conceitual num mesmo fator, com base na frequência de cocitações, utilização de um mesmo par de referências por um mesmo artigo. De modo geral, foram consideradas apenas cargas fatoriais maiores de 0,4 , como pré-requisito para a variável pertencer a um fator (LIN; CHENG, 2010; NERUR; RASHEED; NATARAJAN, 2008; SHAFIQUE, 2013), algumas referências consideradas relevantes foram mantidas, mesmo com valores inferiores a 0,4. Cada fator representa um subtema de pesquisa do tema principal e é formado pelos trabalhos com maior carga fatorial; por meio da análise de cada componente, é validada a formação do fator e este é nomeado.

O escalonamento dimensional (MDS) é uma técnica estatística que auxilia na identificação de similaridades em um conjunto de observações e posiciona esses itens em um diagrama cartesiano, possibilitando, por meio da distância relativa entre eles no espaço dimensional, identificar similaridades, ou seja, quanto mais próximos, maior o grau de similaridade (HAIR; BLACK; BABI; ANDERSON; 2014). O MDS foi conduzido usando as cocitações entre os artigos da amostra, portanto a proximidade entre dois artigos está relacionada à coparticipação deles nos trabalhos constantes da amostra e, quanto mais próximos, maior é a quantidade de vezes em que são cocitados e maior sua similaridade (SHAFIQUE, 2013).

Todos os 449 artigos foram analisados e todas as referências extraídas dos artigos foram 
utilizadas. Os dados foram organizados com o software Bibexcel (PILKINGTON, 2006). Por meio desse software foram obtidas informações sobre frequência de citações e de cocitações. Foram selecionados os 50 artigos com maior frequência de citações (até 10 citações) para continuidade da pesquisa. A matriz de cocitações, após tratamento com o Microsoft Excel é o input para a análise fatorial exploratória realizada com o software SPSS (versão 20).

Pesquisas bibliométricas têm sido usadas por acadêmicos em estudos de estratégia. Ramos-Rodrigues e Ruíz-Navarro (2004) pesquisaram as publicações de um único periódico (Strategic Management Journal); Acedo, Barroso e Galan (2006) estudaram trabalhos envolvendo a RBV e Gaskill, Auken e Manning (1993) causas de declínio em pequenas empresas.

\section{RESULTADOS}

Nesta seção, são apresentados os resultados da análise de citação e de cocitação e a análise fatorial realizada.

\subsection{RESULTADOS DESCRITIVOS}

O Gráfico 1 apresenta a publicação anual dos artigos. A visão da amostra obtida indica que a produção de trabalhos sobre o tema é crescente, como indicado pela curva de tendência. No período pesquisado de 1989 a 2014, 50\% dos trabalhos foram produzidos nos últimos oito anos e cerca de $25 \%$ nos últimos três anos.

A amostra desta pesquisa composta por 449 artigos utilizou 786 autores. A relação dos mais prolíficos encontra-se na Tabela 2. Vale notar que os cinco primeiros tiveram sua produção após 2005, com exceção para D. Shepherd, com três artigos anteriores, fato que comprova a tendência crescente em pesquisas sobre declínio em pequenas empresas. Três temas destacam-se dentre os artigos destes cinco autores: aspectos cognitivos relacionados à aprendizagem com o fracasso e experiência adquirida para favorecer sucesso de novas empreitadas; emoções dos fundadores em criar novas empresas, dirigidos por aproveitamento de oportunidades, ou alternativa para geração de renda e orientação e formulação estratégica com objetivo de prolongar a sobrevivência e buscar desempenho. 
Gráfico 1 - Evolução de publicações em periódicos - 1989-2014

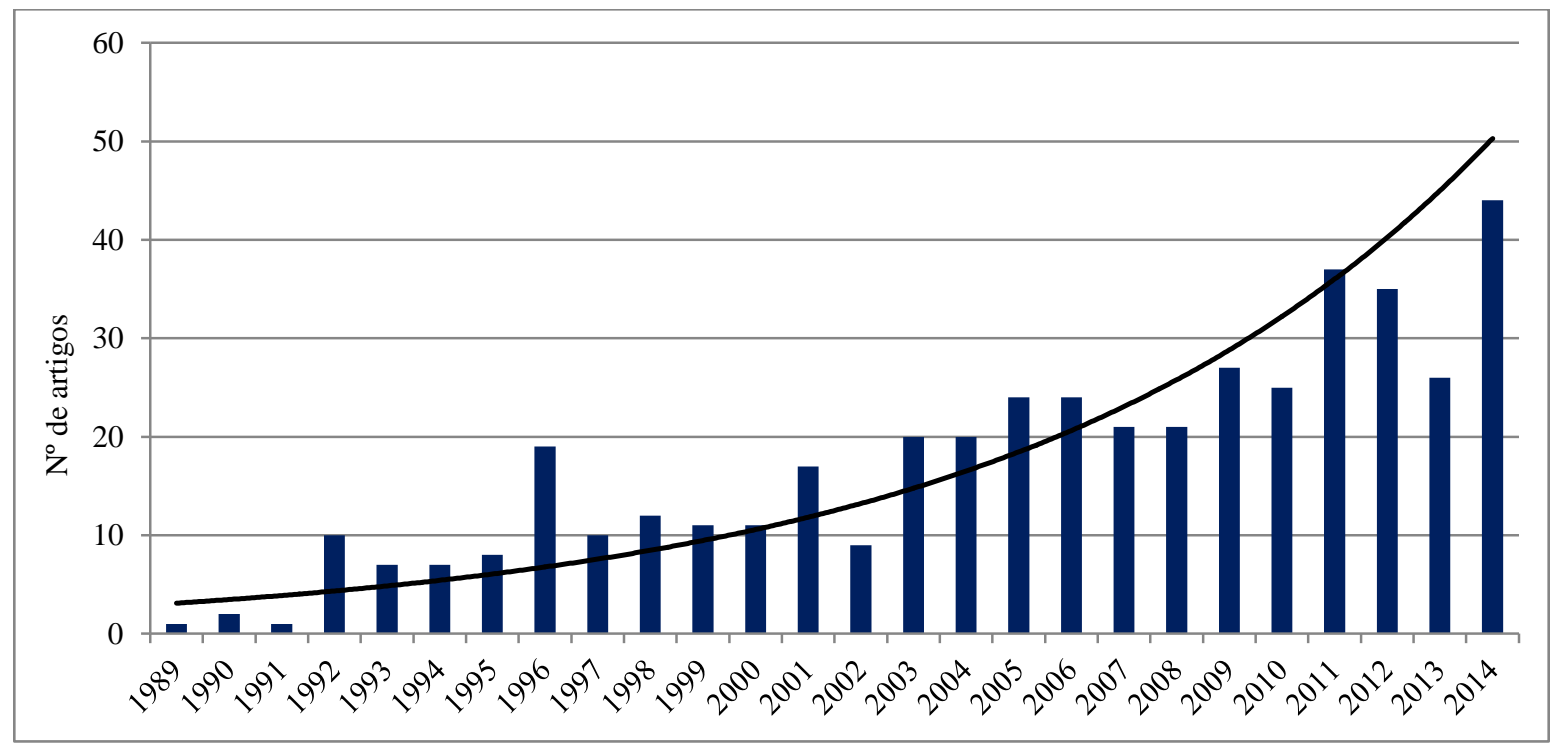

Fonte: ISI - Web of Knowledge

Tabela 2 - Autores mais prolíficos

\begin{tabular}{|c|c|c|c|c|c|c|c|c|}
\hline Rank & Autor & Artigo & Rank & Autor & Artigo & Rank & Autor & Artigo \\
\hline 1 & Shepherd, D. & 14 & $\overline{15}$ & Van Auken, H. & 4 & 29 & Oswald, S. & 3 \\
\hline 2 & Wright, M. & 9 & 16 & Wagner, J. & 4 & 30 & Parker, S. & 3 \\
\hline 3 & Wiklund, J. & 7 & 17 & Wennberg, K. & 4 & 31 & Robbins, D. & 3 \\
\hline 4 & Westhead, P. & 5 & 18 & Chaganti, R. & 3 & 32 & Rutherford, M. & 3 \\
\hline 5 & Cardon, M. & 5 & 19 & Chirico, F. & 3 & 33 & Sarasvathy, S. & 3 \\
\hline 6 & Coad, A. & 4 & 20 & Craig, J. & 3 & 34 & Scholes, L. & 3 \\
\hline 7 & Covin, J. & 4 & 21 & Haynie, J. & 3 & 35 & Simon, $\mathrm{M}$. & 3 \\
\hline 8 & Cowling, M. & 4 & 22 & Houghton, S. & 3 & 36 & Slevin, D. & 3 \\
\hline 9 & Cressy, R. & 4 & 23 & Levie, J. & 3 & 37 & Sohn, S. & 3 \\
\hline 10 & Detienne, D. & 4 & 24 & Lussier, R. & 3 & 38 & Watson, J. & 3 \\
\hline 11 & Meyer, G. & 4 & 25 & Manigart, S. & 3 & 39 & Wilson, N. & 3 \\
\hline 12 & Minnit,i M. & 4 & 26 & Michael, S. & 3 & 40 & Wood, M. & 3 \\
\hline 13 & Pearce, J. & 4 & 27 & Miller, D. & 3 & 41 & Zacharakis, A. & 3 \\
\hline 14 & Ucbasaran, D. & 4 & 28 & Ooghe, H. & 3 & & & \\
\hline
\end{tabular}

Fonte: elaborada pelos autores com base em dados do ISI - Web of Knowledge. 


\subsection{ANÁLISE DE CITAÇÕES}

A análise de citações tem por finalidade a identificação das obras de maior influência na amostra por meio da contagem de vezes em que foi usada. Os 449 trabalhos da amostra usaram 15316 referências, estando as 50 mais citadas na Tabela 3. O mais citado foi o trabalho de Stinchcombe, de 1965, Social Structure and Organizations, com 56 citações (12,5\% da amostra), sobre o efeito da estrutura social na fundação e desempenho e definiu as ameaças decorrentes do noviciado e do porte da empresa. O segundo mais citado, Jovanovic (1982), aborda a relação entre taxas crescimento e de sobrevivência com desempenho. A seguir, Schumpeter (1934) analisa características do empreendedor e seu papel de inovador, demarcando um novo ciclo de prosperidade econômica. O quarto e quinto artigos mais citados são trabalhos de Teoria Baseada em Recursos, definindo condições de aproveitamento de recursos para obtenção de vantagens competitivas (BARNEY, 1991) e condições para o crescimento da empresa (PENROSE, 1959). Essa diversidade de abordagens e de teorias confirma a multidisciplinaridade no estudo de declínio trazida por Serra, Ferreira e Almeida (2013).

Tabela 3 - Trabalhos mais citados

\begin{tabular}{|c|c|c|c|c|c|c|c|c|c|c|}
\hline \multirow[t]{2}{*}{ Referências } & \multicolumn{2}{|c|}{$\begin{array}{l}\text { até } 1999 \\
q=88\end{array}$} & \multicolumn{2}{|c|}{$\begin{array}{l}2000-2004 \\
q=77\end{array}$} & \multicolumn{2}{|c|}{$\begin{array}{l}2005-2009 \\
q=117\end{array}$} & \multicolumn{2}{|c|}{$\begin{array}{l}2010-2014 \\
q=167\end{array}$} & \multicolumn{2}{|c|}{$\begin{array}{l}\text { Total } \\
q=449\end{array}$} \\
\hline & $\mathbf{n}$ & $\%$ & $\mathbf{n}$ & $\%$ & $\mathbf{n}$ & $\%$ & n & $\%$ & $\mathbf{n}$ & $\%$ \\
\hline Stinchcombe (1965) & 12 & 13,6 & 7 & 9,1 & 11 & 9,4 & 26 & 15,6 & 56 & 12,5 \\
\hline Jovanovic (1982) & 9 & 10,2 & 5 & 6,5 & 9 & 7,7 & 22 & 13,2 & 45 & 10,0 \\
\hline Schumpeter (1934) & 10 & 11,4 & 3 & 3,9 & 11 & 9,4 & 16 & 9,6 & 40 & 8,9 \\
\hline Barney (1991) & 2 & 2,3 & 3 & 3,9 & 15 & 12,8 & 19 & 11,4 & 39 & 8,7 \\
\hline Penrose (1959) & 7 & 8,0 & 5 & 6,5 & 11 & 9,4 & 16 & 9,6 & 39 & 8,7 \\
\hline Porter (1980) & 11 & 12,5 & 7 & 9,1 & 9 & 7,7 & 10 & 6,0 & 37 & 8,2 \\
\hline Storey (1994) & 5 & 5,7 & 5 & 6,5 & 15 & 12,8 & 12 & 7,2 & 37 & 8,2 \\
\hline Gimeno-Gascon et al. (1997) & 0 & 0,0 & 1 & 1,3 & 12 & 10,3 & 22 & 13,2 & 35 & 7,8 \\
\hline Aldrich e Auster (1986) & 6 & 6,8 & 7 & 9,1 & 6 & 5,1 & 13 & 7,8 & 32 & 7,1 \\
\hline Dunne, Roberts e Samuelson (1989) & 12 & 13,6 & 6 & 7,8 & 6 & 5,1 & 8 & 4,8 & 32 & 7,1 \\
\hline McGrath (1999) & 0 & 0,0 & 1 & 1,3 & 13 & 11,1 & 18 & 10,8 & 32 & 7,1 \\
\hline Brüderl, Preisendörfer e Ziegler (1992) & 4 & 4,5 & 1 & 1,3 & 9 & 7,7 & 17 & 10,2 & 31 & 6,9 \\
\hline Shepherd (2003) & 0 & 0,0 & 0 & 0,0 & 8 & 6,8 & 23 & 13,8 & 31 & 6,9 \\
\hline
\end{tabular}


Tabela 3 - Trabalhos mais citados

\begin{tabular}{|c|c|c|c|c|c|c|c|c|c|c|}
\hline \multirow[t]{2}{*}{ Referências } & \multicolumn{2}{|c|}{$\begin{array}{l}\text { até } 1999 \\
q=88\end{array}$} & \multicolumn{2}{|c|}{$\begin{array}{l}2000-2004 \\
q=77\end{array}$} & \multicolumn{2}{|c|}{$\begin{array}{l}2005-2009 \\
q=117\end{array}$} & \multicolumn{2}{|c|}{$\begin{array}{l}2010-2014 \\
q=167\end{array}$} & \multicolumn{2}{|c|}{$\begin{array}{l}\text { Total } \\
q=44\end{array}$} \\
\hline & $\mathbf{n}$ & $\%$ & $\mathbf{n}$ & $\%$ & $\mathbf{n}$ & $\%$ & $\mathbf{n}$ & $\%$ & $\mathbf{n}$ & $\%$ \\
\hline Shane e Venkataraman (2000) & 0 & 0,0 & 1 & 1,3 & 11 & 9,4 & 18 & 10,8 & 30 & 6,7 \\
\hline Headd (2003) & 0 & 0,0 & 0 & 0,0 & 8 & 6,8 & 21 & 12,6 & 29 & 6,5 \\
\hline Bruderl e Schussler (1990) & 6 & 6,8 & 4 & 5,2 & 4 & 3,4 & 14 & 8,4 & 28 & 6,2 \\
\hline Porter (1985) & 9 & 10,2 & 6 & 7,8 & 5 & 4,3 & 7 & 4,2 & 27 & 6,0 \\
\hline Ausdretsch (1995) & 4 & 4,5 & 6 & 7,8 & 7 & 6,0 & 9 & 5,4 & 26 & 5,8 \\
\hline Cooper, Gimeno-Gascon e Woo (1994) & 2 & 2,3 & 4 & 5,2 & 10 & 8,5 & 10 & 6,0 & 26 & 5,8 \\
\hline Covin e Slevin (1989) & 5 & 5,7 & 3 & 3,9 & 4 & 3,4 & 14 & 8,4 & 26 & 5,8 \\
\hline Hannan e Freeman (1984) & 5 & 5,7 & 5 & 6,5 & 7 & 6,0 & 9 & 5,4 & 26 & 5,8 \\
\hline Nelson e Winter (1982) & 2 & 2,3 & 4 & 5,2 & 8 & 6,8 & 11 & 6,6 & 25 & 5,6 \\
\hline Eisenhardt e Schoonhoven (1990) & 4 & 4,5 & 3 & 3,9 & 9 & 7,7 & 8 & 4,8 & 24 & 5,3 \\
\hline Evans e Jovanovic (1989) & 7 & 8,0 & 4 & 5,2 & 6 & 5,1 & 7 & 4,2 & 24 & 5,3 \\
\hline Bates (1990) & 4 & 4,5 & 2 & 2,6 & 6 & 5,1 & 11 & 6,6 & 23 & 5,1 \\
\hline Lumpkin e Dess (1996) & 1 & 1,1 & 4 & 5,2 & 6 & 5,1 & 11 & 6,6 & 22 & 4,9 \\
\hline Cohen e Levinthal (1990) & 0 & 0,0 & 5 & 6,5 & 6 & 5,1 & 10 & 6,0 & 21 & 4,7 \\
\hline Geroski (1995) & 0 & 0,0 & 4 & 5,2 & 7 & 6,0 & 10 & 6,0 & 21 & 4,7 \\
\hline Hannan e Freeman (1977) & 6 & 6,8 & 4 & 5,2 & 5 & 4,3 & 6 & 3,6 & 21 & 4,7 \\
\hline Shane e Stuart (2002) & 0 & 0,0 & 0 & 0,0 & 3 & 2,6 & 18 & 10,8 & 21 & 4,7 \\
\hline Ausdretsch (1991) & 3 & 3,4 & 2 & 2,6 & 6 & 5,1 & 9 & 5,4 & 20 & 4,5 \\
\hline Jensen e Meckling (1976) & 1 & 1,1 & 2 & 2,6 & 8 & 6,8 & 9 & 5,4 & 20 & 4,5 \\
\hline Kazanjian (1988) & 7 & 8,0 & 3 & 3,9 & 4 & 3,4 & 6 & 3,6 & 20 & 4,5 \\
\hline Miller (1983) & 3 & 3,4 & 2 & 2,6 & 5 & 4,3 & 10 & 6,0 & 20 & 4,5 \\
\hline Aldrich e Fiol (1994) & 1 & 1,1 & 3 & 3,9 & 8 & 6,8 & 7 & 4,2 & 19 & 4,2 \\
\hline Busenitz e Barney (1997) & 0 & 0,0 & 3 & 3,9 & 9 & 7,7 & 7 & 4,2 & 19 & 4,2 \\
\hline Dunne, Roberts, e Samuelson (1988) & 6 & 6,8 & 3 & 3,9 & 7 & 6,0 & 3 & 1,8 & 19 & 4,2 \\
\hline Evans e Leighton (1989) & 3 & 3,4 & 2 & 2,6 & 3 & 2,6 & 11 & 6,6 & 19 & 4,2 \\
\hline Freeman et al. (1983) & 2 & 2,3 & 1 & 1,3 & 7 & 6,0 & 9 & 5,4 & 19 & 4,2 \\
\hline March (1991) & 0 & 0,0 & 1 & 1,3 & 5 & 4,3 & 13 & 7,8 & 19 & 4,2 \\
\hline Cyert e March (1963) & 5 & 5,7 & 3 & 3,9 & 3 & 2,6 & 7 & 4,2 & 18 & 4,0 \\
\hline Davidsson e Honig (2003) & 0 & 0,0 & 0 & 0,0 & 5 & 4,3 & 13 & 7,8 & 18 & 4,0 \\
\hline Klepper (1996) & 1 & 1,1 & 3 & 3,9 & 3 & 2,6 & 11 & 6,6 & 18 & 4,0 \\
\hline Shane (2000) & 0 & 0,0 & 0 & 0,0 & 7 & 6,0 & 11 & 6,6 & 18 & 4,0 \\
\hline Acs e Ausdretsch (1990) & 3 & 3,4 & 2 & 2,6 & 9 & 7,7 & 3 & 1,8 & 17 & 3,8 \\
\hline
\end{tabular}


Tabela 3 - Trabalhos mais citados

\begin{tabular}{|c|c|c|c|c|c|c|c|c|c|c|}
\hline \multirow{3}{*}{ Referências } & \multirow{2}{*}{\multicolumn{2}{|c|}{$\begin{array}{l}\text { até } 1999 \\
q=88\end{array}$}} & \multirow{2}{*}{\multicolumn{2}{|c|}{$\begin{array}{l}2000-2004 \\
q=77\end{array}$}} & \multirow{2}{*}{\multicolumn{2}{|c|}{$\begin{array}{l}2005-2009 \\
q=117\end{array}$}} & \multirow{2}{*}{\multicolumn{2}{|c|}{$\begin{array}{l}2010-2014 \\
q=167\end{array}$}} & \multirow{2}{*}{\multicolumn{2}{|c|}{$\begin{array}{l}\text { Total } \\
q=449\end{array}$}} \\
\hline & & & & & & & & & & \\
\hline & $\mathbf{n}$ & $\%$ & $\mathbf{n}$ & $\%$ & $\mathbf{n}$ & $\%$ & $\mathbf{n}$ & $\%$ & $\mathbf{n}$ & $\%$ \\
\hline Evans (1987) & 5 & 5,7 & 1 & 1,3 & 4 & 3,4 & 7 & 4,2 & 17 & 3,8 \\
\hline Gersick et al. (1997) & 0 & 0,0 & 3 & 3,9 & 8 & 6,8 & 6 & 3,6 & 17 & 3,8 \\
\hline Holtz-Eakin, Joulfaian e Rosen (1994) & 3 & 3,4 & 3 & 3,9 & 2 & 1,7 & 9 & 5,4 & 17 & 3,8 \\
\hline Pfeffer e Salancick (1978) & 5 & 5,7 & 3 & 3,9 & 5 & 4,3 & 4 & 2,4 & 17 & 3,8 \\
\hline Podsakoff, et al. (2003) & 0 & 0,0 & 0 & 0,0 & 4 & 3,4 & 13 & 7,8 & 17 & 3,8 \\
\hline
\end{tabular}

Nota. 1 - q: trabalhos por período. 2 - n: citações no período. 3 - \% da amostra.

Fonte: Fonte: elaborada pelos autores com base em dados do ISI - Web of Knowledge

A relação dos trabalhos mais citados foi dividida em períodos de cinco anos o que permite analisar alterações da influência ao longo do tempo (Tabela 3). Por exemplo, Barney (1991) vem ganhando relevância na pesquisa sobre declínio, enquanto que Porter (1980) vem sendo a cada período, menos utilizado.

\subsection{ANÁLISE DE COCITAÇÕES}

A análise do diagrama resultante do MDS (Figura 1) permite a identificação de agrupamentos de artigos e, pelo conteúdo destes, podem ser reconhecidos temas relacionados ao estudo de declínio organizacional: empreendedorismo e sobrevivência; administração estratégica e desempenho; inovação e evolução e liabilities e ambiente. É importante notar que esses temas foram confirmados por meio do uso de outra técnica estatística, a análise fatorial exploratória (Tabela 4).

\subsection{ANÁLISE DOS TEMAS INVESTIGADOS - ANÁLISE FATORIAL}

A análise de cocitação mede o grau de ligação de um par de artigos, pelo número de documentos onde esses artigos são citados, simultaneamente (GUEDES; BORSCHIVER, 2005). O resultado obtido permite, por meio de uma análise fatorial exploratória, obter agrupamentos de autores e trabalhos determinados pela similaridade percebida entre eles (LIN; CHENG, 2010), Tabela 4. Os grupos ou fatores representam as abordagens teóricas usadas na amostra e são 
nomeados após leitura dos trabalhos para identificação da teoria abordada e de como se relacionam (RAMOS-RODRÍGUEZ; RUÍZ-NAVARRO, 2004). Os quatro fatores resultantes desta análise fatorial, processada pelo software SPSS, versão 20, foram nomeados conforme segue: empreendedorismo e sobrevivência; administração estratégica e desempenho; inovação e evolução e liabilities $^{4}$ e ambiente e explicam 51,2\% da variância da amostra dos 50 trabalhos mais citados. As cargas fatoriais, colocadas logo após a identificação da referência representa o quanto o dado artigo pertence ao fator. A análise fatorial foi processada para todo o período e para cada subperíodo de cinco anos.

Figura 1 - Diagrama de cocitações dos trabalhos mais citados

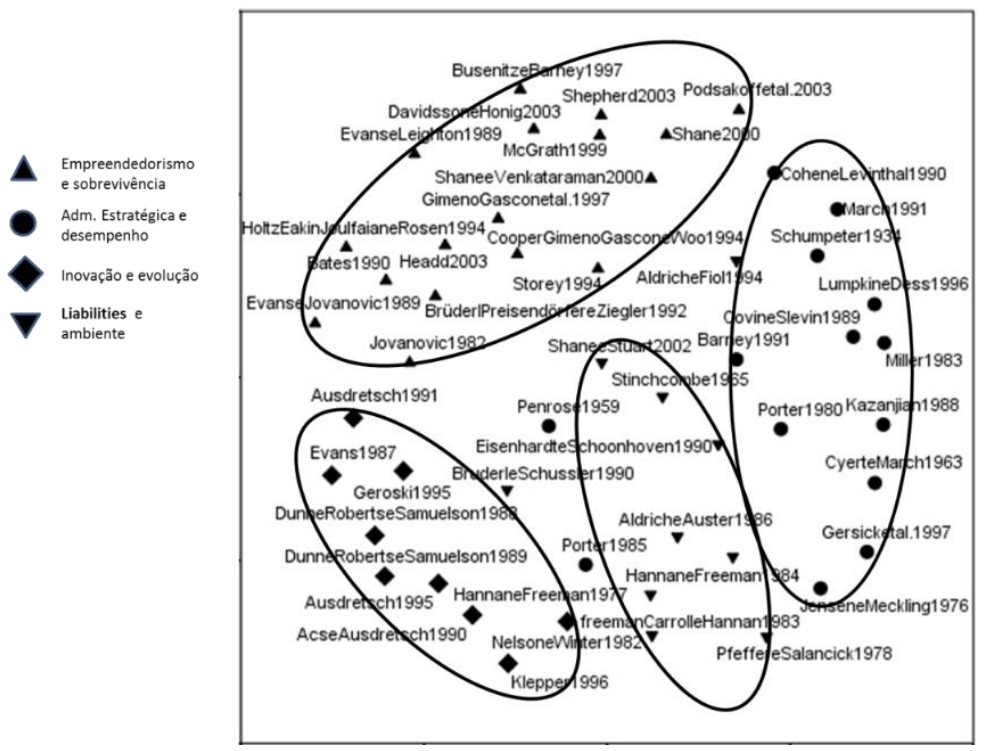

Fonte: elaborada pelos autores usando o SPSS.

Todos os trabalhos foram avaliados para compreender como se relacionavam a partir do seu conteúdo. O primeiro fator que abrange o período total (1989-2014) tem 17 trabalhos e foi denominado Empreendedorismo e Sobrevivência. O trabalho com maior correlação com o fator é o de Headd (2003), sobre o encerramento da empresa por opção do empreendedor com a finalidade de realizar capital ou reorientação de recursos. Seguem os trabalhos de Evans e Leighton (1989), numa complementação ao de Knight (1921), sobre percepção de risco e escolhas do empreendedor; Davidsson e Honig (2003) sobre influência de capital humano e

\footnotetext{
${ }^{4}$ Liabilities: mantido no original. Tem o sentido de ameaça ou desvantagem.
} 
social na criação de novos negócios; e Busenitz e Barney (1997) que investiga diferenças entre empreendedores e gestores em tomadas de decisão.

Tabela 4 - Identificação dos temas investigados

\begin{tabular}{|c|c|c|c|c|c|c|c|}
\hline \multicolumn{8}{|c|}{ Fatores } \\
\hline \multicolumn{2}{|c|}{$\begin{array}{l}\text { Empreendedorismo e } \\
\text { Sobrevivência }\end{array}$} & \multicolumn{2}{|c|}{$\begin{array}{l}\text { Adm. Estratégica e } \\
\text { Desempenho }\end{array}$} & \multicolumn{2}{|c|}{ Inovação e Evolução } & \multicolumn{2}{|c|}{ Liabilities e Ambiente } \\
\hline Headd (2003) & ,770 & $\begin{array}{l}\text { Lumpkin e Dess } \\
\text { (1996) }\end{array}$ & ,721 & Klepper (1996) & ,790 & $\begin{array}{l}\text { Hannan e Freeman } \\
\text { (1984) }\end{array}$ & ,798 \\
\hline $\begin{array}{l}\text { Evans e Leighton } \\
\text { (1989) }\end{array}$ & ,769 & March (1991) & ,697 & Evans (1987) & ,786 & $\begin{array}{l}\text { Aldrich e Auster } \\
\text { (1986) }\end{array}$ & ,737 \\
\hline $\begin{array}{l}\text { Davidsson e Honig } \\
\text { (2003) }\end{array}$ & ,763 & $\begin{array}{l}\text { Schumpeter } \\
\text { (1934) }\end{array}$ & ,691 & $\begin{array}{l}\text { Acs e Ausdretsch } \\
\text { (1990) }\end{array}$ & ,739 & $\begin{array}{l}\text { Eisenhardt e } \\
\text { Schoonhoven (1990) }\end{array}$ & ,723 \\
\hline $\begin{array}{l}\text { Busenitz e Barney } \\
\text { (1997) }\end{array}$ &, 758 & $\begin{array}{l}\text { Covin e Slevin } \\
(1989)\end{array}$ & ,687 & Geroski (1995) & ,682 & $\begin{array}{l}\text { Freeman, Carroll e } \\
\text { Hannan (1983) }\end{array}$ & ,695 \\
\hline $\begin{array}{l}\text { Gimeno-Gascon et al. } \\
\text { (1997) }\end{array}$ & ,739 & $\begin{array}{l}\text { Jensen e } \\
\text { Meckling (1976) }\end{array}$ & ,619 & $\begin{array}{l}\text { Nelson e Winter } \\
(1982)\end{array}$ & ,608 & Aldrich e Fiol (1994) & ,688 \\
\hline Shepherd (2003) &, 714 & Miller (1983) & ,614 & Ausdretsch (1991) &, 587 & $\begin{array}{l}\text { Hannan e Freeman } \\
\text { (1977) }\end{array}$ & ,665 \\
\hline McGrath (1999) &, 709 & $\begin{array}{l}\text { Gersick et al. } \\
\text { (1997) }\end{array}$ & ,611 & Ausdretsch (1995) &, 587 & Stinchcombe (1965) & ,578 \\
\hline $\begin{array}{l}\text { Cooper, Gimeno- } \\
\text { Gascon e Woo (1994) }\end{array}$ & 672 & Porter (1980) &, 554 & $\begin{array}{l}\text { Dunne, Roberts e } \\
\text { Samuelson (1988) }\end{array}$ &, 534 & Shane e Stuart (2002) &, 576 \\
\hline Shane (2000) & 623 & Kazanjian (1988) &, 522 & $\begin{array}{l}\text { Dunne, Roberts e } \\
\text { Samuelson (1989) }\end{array}$ & ,465 & $\begin{array}{l}\text { Pfeffer e Salancick } \\
\text { (1978) }\end{array}$ &, 469 \\
\hline $\begin{array}{l}\text { Shane e Venkataraman } \\
(2000)\end{array}$ & 620 & $\begin{array}{l}\text { Cyert e March } \\
\text { (1963) }\end{array}$ & ,459 & & & $\begin{array}{l}\text { Bruderl e Schussler } \\
\text { (1990) }\end{array}$ & ,433 \\
\hline $\begin{array}{l}\text { Brüderl, Preisendörfer e } \\
\text { Ziegler (1992) }\end{array}$ & 605 & $\begin{array}{l}\text { Cohen e Levinthal } \\
\text { (1990) }\end{array}$ &, 435 & & & & \\
\hline $\begin{array}{l}\text { Holtz-Eakin, Joulfaian e } \\
\text { Rosen (1994) }\end{array}$ & ,602 & Porter (1985) & ,418 & & & & \\
\hline Bates (1990) &, 586 & Barney (1991) &, 393 & & & & \\
\hline Podsakoff et al. (2003) &, 534 & Penrose (1959) &, 342 & & & & \\
\hline Storey (1994) & ,460 & & & & & & \\
\hline Jovanovic (1982) & ,441 & & & & & & \\
\hline $\begin{array}{l}\text { Evans e Jovanovic } \\
\text { (1989) }\end{array}$ & ,438 & & & & & & \\
\hline
\end{tabular}

Fonte: elaborada pelos autores usando SPSS com dados do ISI - Web of Knowledge,

O segundo fator, nomeado de Administração Estratégica e Desempenho, tem 14 trabalhos, e o de maior identificação com o fator é o de Lumpkin e Dess (1996) sobre efeitos da proatividade e agressividade competitiva na formulação estratégica; March (1991) que trata 
efeitos ao desempenho advindos de estratégias de exploração de recursos internos ou busca de novos recursos; Schumpeter (1934) sobre papel do empresário inovador; Covin e Slevin (1989) sobre sobrevivência em ambiente hostil e Jensen e Meckling (1976) sobre aspectos de agência, por exemplo, relacionamento entre o capitalista investidor e o gestor.

O terceiro fator, Inovação e Evolução, tem como característica o fato de pequenas empresas trazerem inovações, principalmente tecnológicas, proporcionando evolução para a indústria. Dentre os componentes, Klepper (1996) abordou inovação e capabilidades inovativas como estratégia de entrada; Evans (1987) abordou aspectos dinâmicos para a sobrevivência; Acs e Audretsch (1990) trataram da importância das empresas de pequeno porte na geração de inovações tecnológicas; Geroski (1995) investigou entradas de pequenas empresas e papel de inovações trazidas por elas no desenvolvimento da indústria e Nelson e Winter (1982) que trataram da evolução tecnológica como meio de evolução e estruturação do mercado.

O quarto fator, denominado de Liabilities e Ambiente, traz as várias ameaças ou liabilities que são associadas às empresas de pequeno porte pela literatura acadêmica. São analisadas as liabilities de idade, porte e estrutural (HANNAN; FREEMAN, 1984; ALDRICH; AUSTER, 1986). Eisenhardt e Schoonhoven (1990) abordaram as influências do ambiente e Freeman, Carroll e Hannan (1983) discutiram liability of newness, ou seja, dependência da idade para sobreviver. A pouca idade traz problemas como falta de reconhecimento por fornecedores, competidores e clientes fatores que levam à escassez de crédito e dificuldades em ganhar mercado ou obter contratos favoráveis com fornecedores (Stinchcombe 1965).

A análise fatorial processada para os subperíodos de cinco anos objetivou mostrar a evolução das abordagens teóricas com que os estudiosos investigaram o processo de declínio organizacional. Os trabalhos e cargas fatoriais para cada cinco anos estão relacionados no Quadro 1. Importante notar que nos três períodos analisados a investigação das causas de declínio passaram por três grandes temas, constantes, mas com algumas variações ao longo do tempo: sobrevivência, estratégia e adaptação. 
Quadro 1 - Temas pesquisados por período

\begin{tabular}{|c|c|c|}
\hline \multirow{3}{*}{ 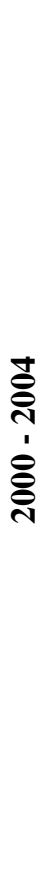 } & Condições para Competitividade & $\begin{array}{l}\text { Teece (1986) - 0,843 } \\
\text { Hannan; Freeman (1977) - 0,839 } \\
\text { Covin; Slevin (1990) - 0,804; } \\
\text { Porter (1980) - 0,790 } \\
\text { Tversky; Kahneman (1974) - 0,727 } \\
\text { Cooper; Artz (1995) - 0,727 } \\
\text { Lumpkin; Dess (1996) - 0,720 } \\
\text { Lieberman; } \\
\text { Montgomery (1988) - 0,641. }\end{array}$ \\
\hline & Evolução da Indústria & $\begin{array}{l}\text { Geroski (1995) - 0,808 } \\
\text { Mata; Portugal; Guimaraes (1995) - 0,778 } \\
\text { Jovanovic (1982) - 0,684 } \\
\text { Audretsch (1995) - 0,680 } \\
\text { Penrose (1959) - 0,673 } \\
\text { Baldwin (1995) - 0,635 } \\
\text { Dunne; Roberts; Samuelson (1989) - 0,630 } \\
\text { Evans; Jovanovic (1989) - 0,607 } \\
\text { Hannan; Freeman (1989) - 0,606 }\end{array}$ \\
\hline & Sobrevivência & $\begin{array}{l}\text { Bruderl; Schussler (1990) - 0,765 } \\
\text { Aldrich, Auster (1986) - 0,664 } \\
\text { Cooper; Gimeno-Gascon; Woo (1994) - 0,656 } \\
\text { Cohen; Levinthal (1990) - 0,628 }\end{array}$ \\
\hline \multirow{4}{*}{ 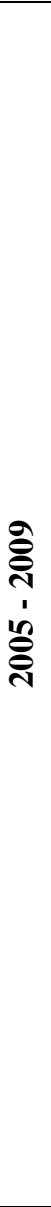 } & Empreendedorismo e Aprendizagem & $\begin{array}{l}\text { Sitkin (1992) - 0,875 } \\
\text { Shane (2000) - 0,805 } \\
\text { Westhead, Wright (1998) - 0,791 } \\
\text { Shepherd (2003) - 0,746 } \\
\text { MacMillan; Siegel; Narasimha (1985) - } 0,714 \\
\text { McGrath (1999) - 0,708 } \\
\text { Shane; Venkataraman (2000) - 0,704 } \\
\text { Gartner (1985) - 0,667 } \\
\text { Busenitz; Barney (1997) - 0,654 } \\
\text { Cohen; Levinthal (1990) - 0,640 } \\
\text { Storey (1994) - 0,639 } \\
\text { Gimeno; Folta; Cooper; Woo ( !997) - 0,608 }\end{array}$ \\
\hline & Abordagens Conceituais & $\begin{array}{l}\text { Stinchcombe (1965) - 0,789 } \\
\text { Freeman: Carroll; Hannan (1983) - 0,778 } \\
\text { Hannan; Freeman (1984) - 0,769 } \\
\text { Aldrich; Fiol (1994) - 0,760 } \\
\text { Eisenhardt; Schoonhoven (1990) - 0,759 } \\
\text { Porter (1980) - 0,715 } \\
\text { Penrose (1959) - 0,652 } \\
\text { Barney (1991) - 0,611 }\end{array}$ \\
\hline & Condições de Entrada e Sobrevivência & $\begin{array}{l}\text { Geroski (1995) - 0,722 } \\
\text { Wagner (1994) - 0,693 } \\
\text { Audretsch (1995) - 0,657 } \\
\text { Audretsch (1991) - 0,648 } \\
\text { Acs; Audretsch (1990) - 0,612 } \\
\text { Dunne; Roberts; Samuelson (1988) - 0,604 }\end{array}$ \\
\hline & Empresas Familiares & $\begin{array}{l}\text { Habbershon; Williams (1999) - 0,767 } \\
\text { Gersick et al. (1997) - 0,665 } \\
\text { Sharma (2004) - 0,643 } \\
\text { Schulze et al. (2001) - 0,628 }\end{array}$ \\
\hline
\end{tabular}


Quadro 1 - Temas pesquisados por período

(conclusão)

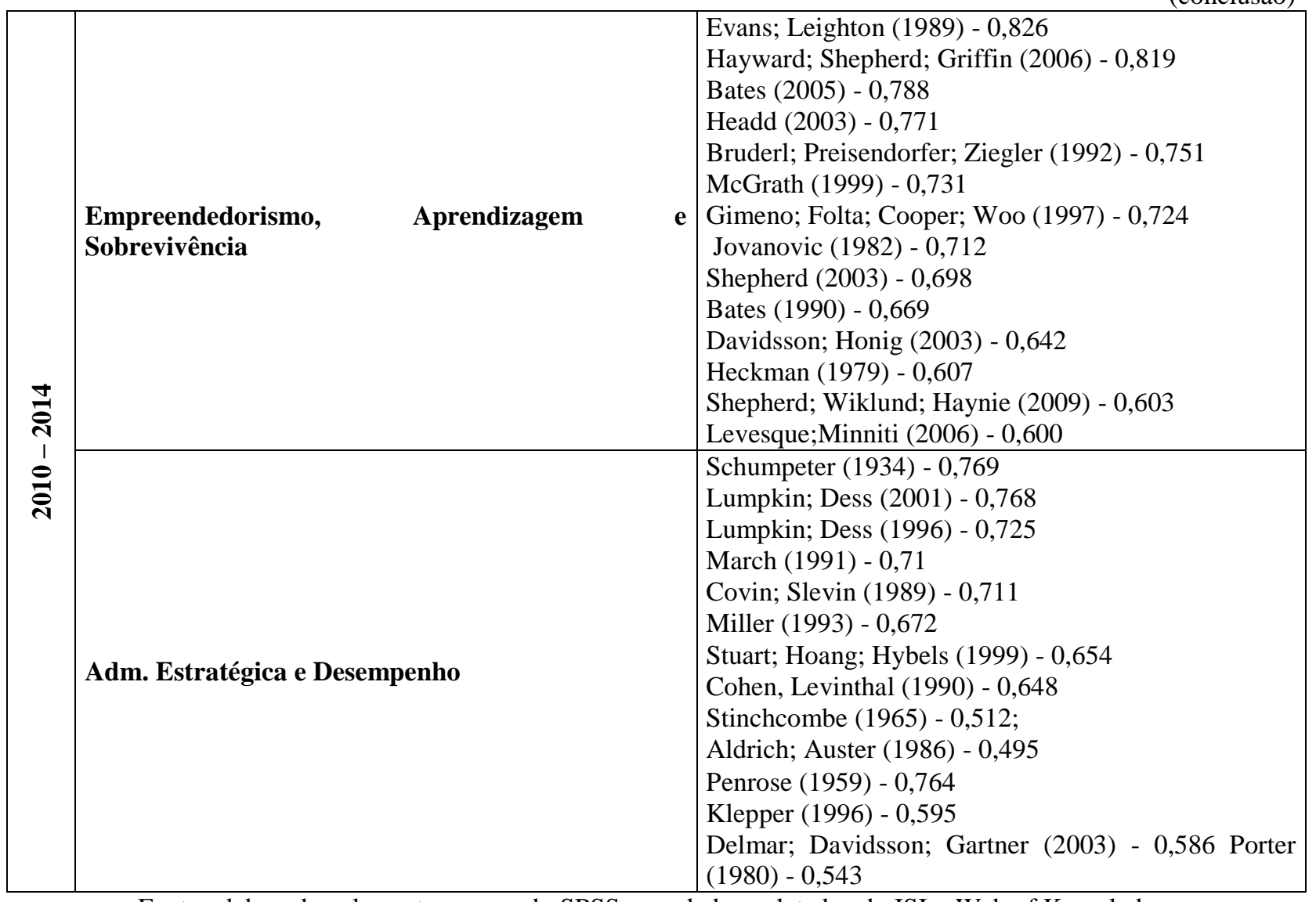

Fonte: elaborada pelos autores usando SPSS com dados coletados do ISI - Web of Knowledge.

Para o primeiro período foram usados 76 dos 449 artigos da amostra. Foram obtidos três fatores com $53 \%$ da variância explicada. Cada subfator, pela proximidade conceitual determinada pela análise fatorial, foi nomeado. Em Condições para Competitividade são relacionados fatores impulsionadores da competitividade: Teece (1986) abordou a inovação; Hannan e Freeman (1977) trouxeram a necessidade de adaptação; Covin e Slevin (1990) abordaram postura estratégica e desempenho. O segundo subfator, Evolução da Indústria, tem vários trabalhos sobre condições de entrada de novas empresas (DUNNE; ROBERTS; SAMUELSON, 1989; GEROSKI; 1995; MATA; PORTUGAL; GUIMARAES, 1995) e o papel que empresas de pequeno porte têm na evolução de determinada indústria, seja por trazerem inovações ou por serem vetores da seleção dentro da indústria (JOVANOVIC, 1982; AUDRETSCH, 1995). O terceiro subfator, Sobrevivência, traz artigos sobre riscos à sobrevivência, como problemas de infância e de adolescência (BRUDERL; SCHUSSER, 1990) e necessidade de aprendizagem para mitigar riscos (COHEN; LEVINTHAL, 1990; COOPER; GIMENO-GASCON; WOO, 1994). 
Para o segundo período, foram considerados 117 trabalhos e obtidos quatro fatores com $50 \%$ da variância explicada. O primeiro subfator, Empreendedorismo e Aprendizagem, tem seus principais artigos discutindo aprendizagem sob diversos aspectos. Experiência no fracasso e a aprendizagem obtida são importantes fatores para sucesso em outras novas empresas (MACMILLAN; SIEGEL; NARASIMHA, 1985; MCGRATH, 1999; SHEPHERD, 2003; SITKIN, 1992). Liabilities e Adaptação traz riscos para a empresa abordados sob os aspectos de idade e tamanho (STINCHCOMBE, 1965; ALDRICH; FIOL, 1994) e aspectos de adaptação para reduzir possibilidade de declínio, incluindo o aproveitamento de recursos internos (PENROSE, 1959; PORTER, 1980; EISENHARDT; SCHOOHOVEN, 1990; BARNEY, 1991). Condições de Entrada e Sobrevivência aborda os vários aspectos da entrada de uma nova empresa no ambiente de negócios (AUDRETSCH, 1991, 1995; GEROSKI, 1995; WAGNER, 1994). Finalmente, neste segundo período, é formado um fator para Empresas Familiares, abordando recursos idiossincráticos (HABBERSHON, WILLIAMS, 1999), relações de sucessão (GERSICK, DAVIS, HAMPTON, LANSBERG, 1997) e de agência (SCHULZE, LUBATKIN, DINO, BUCHHOLTZ, 2001). É importante notar que este período foi o único a apresentar uma concentração de trabalhos sobre empresas familiares, a ponto de formarem um fator exclusivo. A pesquisa sobre empresas familiares é uma importante vertente da pesquisa sobre empresas de pequeno porte e características específicas como sucessão, capital humano e social e relações de oportunismo precisam ser vistas de forma própria (SHARMA, 2004).

O terceiro período é composto por 167 artigos e foram obtidos dois fatores com $52 \%$ da variância explicada. Empreendedorismo: Aprendizagem e Sobrevivência é o primeiro subfator. $\mathrm{O}$ empreendedorismo é abordado em relação à escolha da oportunidade e o aprendizado decorrente (EVANS; LEIGHTON, 1989), sob o aspecto do excesso de confiança que pode provocar o fracasso da empresa (HAYWARD ET AL., 2006) e sob a forma de causas próprias do processo empreendedorista para o fechamento da empresa (BATES, 2005; HEADD, 2003). O segundo subfator foi denominado Adm. Estratégica e Desempenho e traz artigos que abordaram aspectos relacionados à formulação estratégica (DELMAR; DAVIDSSON; GARTNER, 2003; LUMPKIN; DESS, 1996, 2001; MILLER, 1983) e à sobrevivência (ALDRICH; AUSTER, 1986; PENROSE, 1959; STUART, HOANG; HYBELS, 1999).

\section{DISCUSSÃO}


Neste estudo foi conduzida uma pesquisa para verificar os principais trabalhos e abordagens teóricas que delimitam o conhecimento acadêmico sobre declínio em pequenas empresas. Para tal, foram coletados em nove conceituados periódicos, artigos que abordaram declínio organizacional. Foram obtidos e validados 449 artigos publicados a partir de 1989, constituindo a amostra com a qual foi conduzida esta pesquisa. O método de pesquisa foi a bibliometria, baseado em técnicas de citação e cocitação, além disso, foi conduzida uma análise fatorial exploratória e escalonamento dimensional para todo o período e para subperíodos de cinco anos.

Os objetivos desta pesquisa foram: identificar as pesquisas e autores mais influentes; apontar como as abordagens empregadas evoluíram ao longo do período da pesquisa; e como se inter-relacionam, formando a estrutura da pesquisa sobre declínio. Foram identificadas quatro linhas usadas em estudos de declínio em empresas de pequeno porte: Aspectos de Empreendedorismo e Sobrevivência; Administração Estratégica e Desempenho; Inovação e Evolução da Indústria e Liabilities e Ambiente.

As quatro vertentes de análise do processo de declínio apontaram para fatores internos e externos. As pesquisas se amparam em teorias que focam essas duas dimensões. Fatores externos são os que implicam numa transação entre a empresa e o meio ambiente e são, nos estudos sobre declínio, relacionados à idade, tamanho e adaptação contidos nas perspectivas da ecologia, e também fatores ligados ao ciclo de vida, reconhecimento de oportunidades e competitividade ancoradas na teoria porteriana. Fatores internos estão ligados à exploração e prospecção de recursos e à governança, principalmente em aspectos de aprendizagem e tomada de decisões. Aspectos ligados ao empreendedorismo e adaptação ao ambiente, superando pressões institucionais e pressões de mercado têm maior externalidade. A ação empreendedora traz subjacente a adoção de risco e incerteza quanto ao sucesso da empresa. As ameaças são muitas no começo de vida da empresa, associadas ao pequeno porte e à complexidade que envolve a conquista da legitimidade junto aos atores externos, condição indispensável para superar os primeiros anos.

Ações ligadas a inovações e formulação estratégica estão concentradas no centro da empresa e implicam no uso eficiente de recursos, esforços de inovações, adaptação e tomada de decisões. As dimensões internas, se bem resolvidas, levam ao equacionamento das ameaças externas. O grau de internalidade/externalidade está representado na Figura 2 e permite inferir 
que as dimensões se inter-relacionam, não existindo isoladamente e, continuamente, redimensionando os limites da empresa. Essa conexão entre aspectos internos e externos aumenta a complexidade da gestão da pequena empresa, constituindo-se num desafio à sobrevivência (MELLAHI; WILKINSON, 2004). Por exemplo, iniciativas inovadoras concorrem em melhor aproveitar as oportunidades e reduzir riscos pela primazia no mercado, mas por outro lado, devido à falta de legitimidade, não encontram apoio para auferir todos os benefícios dessa iniciativa.

Figura 2 - Fatores / Abordagens conceituais

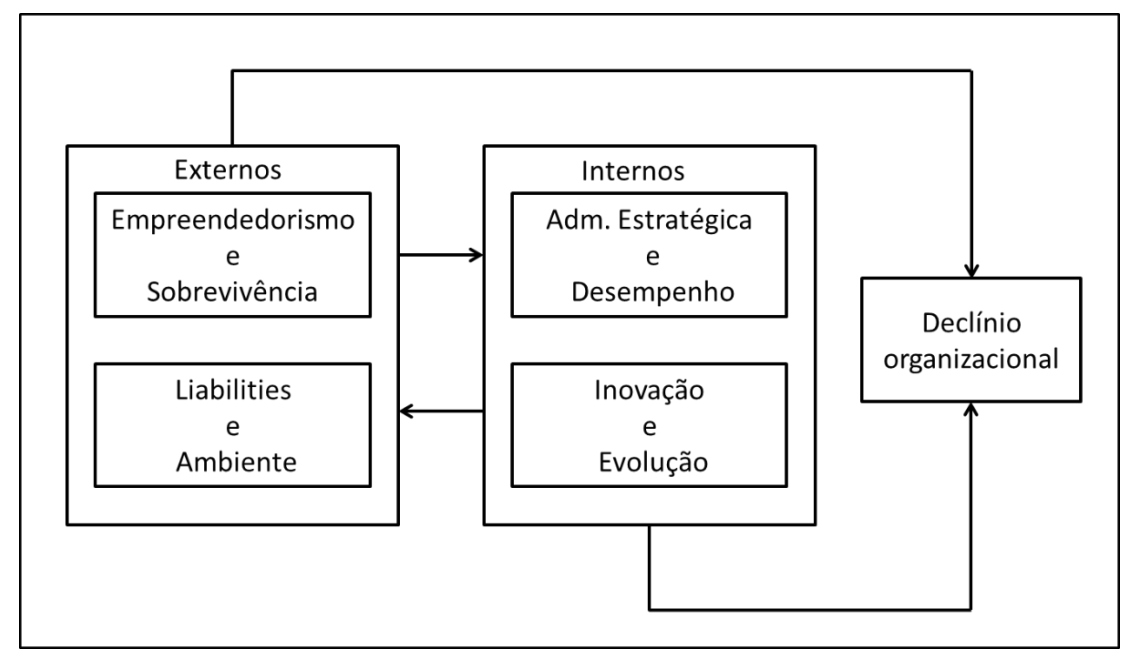

Fonte: elaborado pelos autores.

Este achado da pesquisa além de ser consistente com pesquisas anteriores que apontam para causas internas e externas no desencadear do declínio (WEITZEL; JONSSON, 1989; VENKATARAMAN; VAN DEN VEM, 1998; TOWSAND; BUSENITZ; ARTHURS, 2010), traz uma nova visão, pois, ao contrário destas, não é reducionista apontando para umas ou outras, mas as considera simultaneamente como indutoras do declínio. Frequentemente, o não reconhecimento de aspectos ambientais, como conjuntura macroeconômica, alterações nas regras da competição ou na cadeia de fornecimento não são identificados, levando ao declínio. A literatura aponta para as liabilities de idade, tamanho e complexidade como fatores indutores, contemplando causas específicas como inexperiência de gestores, desconhecimento do mercado e limitação a crédito que, em pequenas empresas são mais agudos, devido à maior fragilidade, em termos de recursos. Situações em que a rápida reorientação estratégica ou adaptação são 
necessárias, para as pequenas empresas são de mais difícil percepção (TOWNSEND; BUSENITZ, 2015; UCBASARAN; WESTHEAD; WRIGHT, 2009). Isto pode ser explicado pela teoria da inércia organizacional ou por aspectos institucionais que levam à redução da folga de recursos e ao fracasso da empresa. Trabalhos de ecologia organizacional, organização industrial e teoria baseada em recursos foram encontrados em todos os períodos analisados, suportando pesquisas sobre competitividade, sobrevivência, riscos e aprendizagem.

Dentre os aspectos internos, destacam-se aprendizagem contínua para mitigação de riscos, definição de estratégias e de metas, percepção de riscos e gestão eficiente de recursos já que as folgas dos vários tipos de recursos são escassas, levando as pequenas empresas a terem dificuldades em absorver alterações conjunturais e falha em tomada de decisões, seja sobre escolha de portfolio de produtos ou em identificar oportunidades de mercado ou ainda na utilização de recursos financeiros (TORNIKOSKI; NEWBERT, 2007; VERHEES; MEULENBERG, 2004). Uma pequena empresa deve utilizar eficientemente os recursos disponíveis e aprender a reconhecer quando esses recursos precisam ser combinados com novos recursos a serem obtidos no mercado para promover desempenho e sobrevivência, portanto, o desenvolvimento de capacidades dinâmicas e da ambidesteridade levam à postergação do declínio (MARCH, 1991; TOWNSEND; BUSENITZ, 2015).

Aspectos de empreendedorismo são subjacentes ao estudo de pequenas empresas e constituem fatores limítrofes entre o ambiente interno e externo e podem tornar-se proteção ou ameaça no fracasso da empresa. Foram encontrados na pesquisa de diferentes formas, como visão estratégica para avaliação de riscos e de oportunidades, como em Shane (2000), ou na sequência de fechamentos e aberturas de novas empresas, usada por alguns empreendedores como forma de correção de rumos ou de realização de lucros (BATES, 1995) ou ainda no excesso de confiança levando a problemas de gestão (HAYWARD; SHEPHERD; GRIFFIN, 2006).

A visão longitudinal das vertentes de pesquisa empregadas pela academia para estudo do declínio, identificadas pela análise dos subperíodos de cinco anos, converge para os fatores apontados na análise da amostra total referente ao período investigado. Mais uma vez fatores internos e externos contribuem para a explicação do declínio, não havendo preponderância de uns sobre os outros, mas ambos levando de modo simultâneo e inter-relacionado ao declínio organizacional. Os números antes de cada fator indicam, na evolução dos estudos sobre o tema, a convergência destes com os quatro fatores principais obtidos pela análise de toda a amostra. 
É importante notar que o campo de estudos em declínio em pequenas empresas convergiu para a adoção de dois temas. Em primeiro lugar, para os aspectos relacionados à própria existência, indicando a ênfase em reconhecer e entender o que leva ao declínio, tal qual na medicina em que doenças são estudadas para evitá-las e, em segundo lugar, para as influências da estratégia no desempenho e no aumento da longevidade das pequenas empresas (Tabela 5). Este achado da pesquisa contribui para nortear futuros estudos sobre o tema e para orientar os iniciantes no estudo de declínio organizacional em pequenas empresas.

Tabela 5 - Evolução das abordagens conceituais

\begin{tabular}{|c|c|c|c|}
\hline $\begin{array}{c}2000 \text { a } 2004 \text { - } 76 \\
\text { artigos }\end{array}$ & $\begin{array}{c}2005 \text { a } 2009-117 \\
\text { artigos }\end{array}$ & $\begin{array}{c}2010 \text { a } 2014 \text { - } 167 \\
\text { artigos }\end{array}$ & $\begin{array}{c}\text { Toda a amostra - } 449 \\
\text { artigos }\end{array}$ \\
\hline 1. Sobrevivência & $\begin{array}{l}\text { 1. Empreendedorismo } \\
\text { e Aprendizagem } \\
\text { 2. Empresas } \\
\text { Familiares }\end{array}$ & $\begin{array}{l}\text { 1. e } 3 . \\
\text { Empreendedorismo, } \\
\text { Aprendizagem e } \\
\text { Sobrevivência }\end{array}$ & $\begin{array}{l}\text { 1. Empreendedorismo e } \\
\text { Sobrevivência }\end{array}$ \\
\hline $\begin{array}{l}\text { 2. Condições para } \\
\text { Competitividade }\end{array}$ & $\begin{array}{l}\text { 3. Liabilities e } \\
\text { Adaptacão }\end{array}$ & & $\begin{array}{l}\text { 2. Adm. Estratégica e } \\
\text { Desempenho }\end{array}$ \\
\hline & & $\begin{array}{l}\text { 2. e 4. Adm. } \\
\text { Estratégica e } \\
\text { Desempenho }\end{array}$ & 3. Liabilities e Ambiente \\
\hline $\begin{array}{l}\text { 3. Evolução da } \\
\text { Indústria }\end{array}$ & $\begin{array}{l}\text { 4. Condições de } \\
\text { Entrada e } \\
\text { Sobrevivência }\end{array}$ & & 4. Inovação e Evolução \\
\hline
\end{tabular}

Fonte: elaborado pelos autores.

Esta pesquisa complementa estudos anteriores em abrangência de contexto e particularização do objeto. Com relação à Franco e Haase (2010) e Gaskill et al. (1993), esta bibliometria trouxe a associação de causas endógenas e exógenas na deflagração do declínio, além disso, pela abrangência da amostra pesquisada, este achado pode ser generalizado para as empresas de pequeno porte, independentemente do contexto em que se insiram. Franco e Haase (2010) enfatizaram causas externas e restringiram seu estudo a oito empresas portuguesas e Gaskill et al. (1993) a empresas do setor de vestuário. Este estudo complementou o trabalho de Serra et al. (2013), pois tem seu foco em pequenas empresas.

\subsection{LIMITAÇÕES E PESQUISAS FUTURAS}


Este estudo apresenta limitações que são próprias de uma bibliometria. Em primeiro lugar, uma bibliometria tem os resultados determinados pelas medidas utilizadas para avaliar as publicações. Neste trabalho foram empregadas as análises de citação e de cocitação. A análise de citação não considera o contexto no qual a citação foi empregada; uma citação, por exemplo, pode ter sido usada para reforçar um argumento, enquanto que em outro trabalho, para criticá-lo. Autores têm a propensão de citar outros autores que são populares num determinado tema bem como journals de alto fator de impacto numa estratégia de legitimação de seus trabalhos, mais do que pela sua relevância. Assim, trabalhos mais antigos tendem a ser mais citados por serem mais conhecidos. Futuras pesquisas podem definir um intervalo de tempo para a consideração das citações, impedindo que maior impacto seja conferido a trabalhos mais antigos.

A análise de cocitação mede se dois diferentes trabalhos são citados conjuntamente, indicando características similares entre ambos. Contudo, não foi feita uma análise de conteúdo para avaliar como foram citados. Futuros trabalhos podem conjugar uma análise de conteúdo com a de cocitação para estabelecer de modo mais exato a conexão entre os documentos.

Outras limitações dizem respeito à escolha das palavras-chave que, apesar de haverem capturado parte significativa da publicação sobre o tema, não consideraram todos os artigos publicados e aos periódicos que não cobrem toda a pesquisa publicada, ainda que tenham sido eleitos os principais periódicos sobre o tema. Desta maneira, futuros trabalhos podem ampliar a seleção dos periódicos e incluir aqueles especializados em outras áreas como estratégia ou finanças.

Apesar das limitações apresentadas, os estudos bibliométricos reduzem a subjetividade de estudos anteriores cuja seleção dos artigos e a forma de análise tende a ser subjetiva, dependendo de critérios idiossincráticos estabelecidos pelos autores (PARÉ; TRUDEL; JAANA; KITSIOU, 2015).

Este trabalho abre possibilidades de futuras pesquisas tratarem do declínio por meio de modelos conceituais, voltados a grandes empresas (PIERCE; ROBBINS, 1993; TRAHMS; NDOFOR; SIRMON, 2013) ou a pequenas empresas (STINCHCOMBE, 1965; KEATS; BRACKER, 1988). Testar esses modelos, verificar sua adequação para uso em pequenas empresas e sua adequação para empresas brasileiras, permitirá a construção de importante evidência para uso tanto acadêmico como por executivos. A amostra obtida para esta pesquisa permitirá a seleção de informações necessárias para tal. 


\section{CONSIDERAÇÕES FINAIS}

Esta pesquisa tem implicações acadêmicas e gerenciais. Para a academia, permite uma visão evolutiva aos trabalhos anteriores (GASKILL; AUKEN; MANNING, 1993; FRANCO; HAASE, 2010; SERRA; FERREIRA; ALMEIDA, 2013) com a identificação de que causas internas e externas agem simultaneamente para provocar o declínio, e identificar quais as linhas de investigação sobre declínio em pequenas empresas são empregadas. Para os executivos, esta pesquisa, por identificar situações e fatores que levam ao declínio, mostra a importância de perceber e compreender quando o processo se avizinha e adotarem ações para neutralizá-lo.

\section{REFERÊNCIAS}

ACEDO, F.; BARROSO, C.; GALAN, J. The resource-based theory: dissemination and main trends. Strategic Management Journal, v. 27, n. 7, p. 621-636, 2006.

ACS, Z.; AUDRETSCH, D. Innovation and small firms. International Journal of Industrial Organization (Vol. 9). Boston, MA: Massachusettd Institute of Tchnonogy, 1990.

ALDRICH, H. Organizations and Environments. Englewood Cliffs, NJ: Prentice-Hall, 1979. ALDRICH, H., Auster, E. Even dwarfs starred small: liabilities of age and size and their srtategic implications. Research in Organizational Behavior, v. 8, p.165-199, 1986.

ALDRICH, H., Fiol, C. Fools Rush in? The Institutional Context of Industry Creation. The Academy of Management Review, v. 19, n. 4, p.645, 1994.

AUDRETSCH, D. New-firm survival and the technological regime. Review of Economics and Statistics, v. 74, p.441-450, 1991.

AUDRETSCH, D. Innovation and Industry Evolution. Cambridge, MA: MIT Press, 1995. BALDWIN, J. Dynamics of Industrial Competition. Cambridge, UK: Cambridge University Press, 1995.

BARNEY, J. Firm Resources and Sustained Competitive Advantage. Journal of Management, v. 17, n. 1, p.99-120, 1991.

BATES, T. Entrepreneurial human capital inputs and small business longevity. Review of Economics and Statistics, v. 72, n. 4, p.551-559, 1990.

BATES, T. Analysis of young, small firms that have closed: Delineating successful from 
unsuccessful closures. Journal of Business Venturing, v. 20, n. 3, p.343-358, 2005. BRUDERL, J.; PREISENDORFER, P.; ZIEGLER, R. Survival Chances of Newly Founded Business Organizations. American Sociological Review, v. 57, n.(2), p.227, 1992. BRUDERL, J.; SCHUSSLER, R. Organizational Mortality: The Liabilities of Newness and Adolescence. Administrative Science Quarterly, v.35, p.530-547, 1990.

BRUTON, G.; OVIATT, B.; WHITE, M. Performance of acquisitions of distressed firms. Academy of Management Journal, v. 37, n. 4, p.972-989, 1994.

BUSENITZ, L.; BARNEY, J. Differences between entrepreneurs and managers in large organizations: biases and heuristics in strategic decision-making. Journal of Business Venturing, v. 12, n. 1, p.9-30, 1997.

CAMERON, K.; WHETTEN, D.; KIM, M. Organizational dysfunctions of decline. Academy of Management Journal, v. 30, n. 1, p.126-138, 1987.

CHILD, J. Organizational structure, environment and performance: the role of strategic choice. Journal of British Sociological Association, v. 6, n. 1, p.2-22, 1992.

COHEN, W., LEVINTHAL, D. Absorptive capacity: a new perspective on learning and innovation. Administrative Science Quarterly, v. 35, p.118-152, 1990.

COLLINS, J. How the Mighty Fall. London: Randon House Business Books, 2009. COOPER, A.; ARTZ, K. Determinants of satisfaction for entrepreneurs. Journal of Business Venturing, v. 10, n. 6, p.439-457, 1995.

COOPER, A.; GIMENO-GASCON, F.; WOO, C. Initial human and financial capital as predictors of new venture performance. Journal of Business Venturing, v. 9, n. 5, p.371-395, 1994.

COVIN, J.; SLEVIN, D. Strategic management of small firms in hostile and benign environments. Strategic Management Journal, v.10, n. March 1987, p.75-87, 1989.

CULMAN, M.; O'REILLY, C.; CHATMAN, J. Intelectual structure of research in organizational behavior, 1972-1984: a co-citation analysis. Journal of the American Society for Information Sc1ience, v.41, n. 6, p.453-458, 1990.

CYERT, R.; MARCH, J. A Behavioral Theory of the Firm. Englewood Cliffs, NJ: PrenticeHall, 1963.

DAMODARAN, A. The Little Book of Valuation - How to Value a Company, Pick a Stock, and Profit. Hoboken, NJ: John Wiley Sons Inc., 2011. 
DAVIDSSON, P., HONIG, B. The role of social and human capital among nascent entrepreneurs. Journal of Business Venturing, v. 18, n. 3, p.301-331, 2003.

DELMAR, F.; DAVIDSSON, P.; GARTNER, W. Arriving at the high-growth firm. Journal of Business Venturing, v. 18, n. 2, p.189-216, 2003.

DUNNE, T.; ROBERTS, M.; SAMUELSON, L. Patterns of firm entry and exit in United-States manufacturing- industries. Rand Journal of Economics, v. 19, n. 4, p.495-515, 1988.

DUNNE, T.; ROBERTS, M.; SAMUELSON, L. The growth and failure of U.S. manufacturing plants. Quarterly Journal of Economics, v. 104, n. 4, p.671-698, 1989.

EISENHARDT, K.; SCHOONHOVEN, C. Organizational Growth : Linking Founding Team , Strategy . Environment, and Growth among US Semiconductor Ventures. Administrative Science Quarterly, v. 35, n. 3, p.504-529, 1990.

EVANS, D. The relationship between firm growth, size and age: estimates for 100 manufactoring industries. Journal of Industrial Economics, v. 35, p.567-581, 1987.

EVANS, D.; JOVANOVIC, B. An estimated model of entrepreneurial choice under liquidity constraints. Journal of Political Economy, v. 97, n. 4, p.808-827, 1989.

EVANS, D., LEIGHTON, L. Some Empirical Aspects of Entrepreneurship. The American Economic Review, v. 79, p.519-535, 1989.

FABRIGAR, L. R.; WEGENER, D.; MACCALLUN, R. Evaluating the use of exploratory factor analysis in psychological research. Psychological Methods, v. 4, n. 3, p.272-299, 1999.

FERREIRA, M.; MIRANDA, R.; REIS, N.; PINTO, C.; SERRA, F. Pesquisa em empreendedorismo no principal periódico internacional: um estudo bibliométrico das publicações no Journal of Business Venturing entre 1987 e 2010. Revista de Empreendedorismo e Gestão de Pequenas Empresas, v. 3, n. 1, p.56-83, 2014.

FRANCO, M., HAASE, H. Failure factors in small and medium-sized enterprises: qualitative study from an attibutional perspective. International Entrepreneurship and Management Journal, v. 6, n. 4, p.503-521, 2010.

FREEMAN, J.; CARROLL, G.; HANNAN, M. The liability of newness: age dependence in organization death rates. American Sociological Review, v. 48, n. October, p.692-710, 1983. GASKILL, L.; AUKEN, H.; MANNING, R. A factor analytic study of the perceived causes of small business failure. Journal of Small Business Management, v. 31, n. 4, p.18-31, 1993. GEROSKI, P. What do we know about entry? International Journal of Industrial 
Organization, v. 13, n. 4, p.421-440, 1995.

GERSICK, K.; DAVIS, J.; HAMPTON, M.; LANSBERG, I. Generation to Generation. Boston, MA: Harvard Business School Press, 1997.

GUEDES, V.; BORSCHIVER, S. Bibliometria: uma ferramenta estatística para a gestão da informaçao e do conhecimento em sistemas de informaçao, de comunicaçao e de avaliaçao científica e tecnológica. In ICI/UFBA, p.1-18), 2005.

HABBERSHON, T.; WILLIAMS, M. A resource-based framework for assessing the strategic advantages of family firms. Family Business Review, v. 12, n. 1, p.1-25, 1999.

HAMEL, G. What Matters Now: How to Win in a World of Relentless Change, Ferocious Competition, and Unstoppable Innovation. Choice Reviews Online, v. 49. San Francisco. CA: Jossey-Bass, 2012.

HANNAN, M.; CARROLL, G. Dynamics of Organizational Populations: Density, Legitimation and Competition. New York: Oxford University Press, 1992.

HANNAN, M.; FREEMAN, J. The population ecology of organizations. The American Journal of Sociology, v. 82, n. 5, p.929-964, 1977.

HANNAN, M.; FREEMAN, J. Structural inertia and organizational change. American Sociological Review, v. 49, p.149-164, 1984.

HANNAN, M.; FREEMAN, J. Organizational Ecology. Cambridge, MA: Harvard University Press, 1989.

HAYWARD, M.; SHEPHERD, D.; GRIFFIN, D. A Hubris Theory of Entrepreneurship. Management Science, v. 52, n. 2, p.160-172, 2006.

HEADD, B. Redefining Business Success: Distinguishing between Closure and Failure. Small Business Economics, v. 2, n. 1, p.51-61, 2003.

HOLTZ-EAKIN, D.; JOULFAIAN, D.; ROSEN, H. Sticking it out: entrepreneurial survival and liquidity constraints. Journal of Political Economy, v. 102, n. 1, p.53-75, 1994.

JENSEN, M.; MECKLING, W. Theory of the Firm : Managerial Behavior, Agency Costs and Ownership Structure. Journal of Financial Economics, v. 3, n. 4, p.305-360, 1976.

JOVANOVIC, B. Selection and the evolution of industry. Econometrica, v. 50, n. 3, p.649-670, 1982.

KAHNEMAN, D.; TVERSKY, A. Prospect theory: an analysis of decision under risk.

Econometrica, v. 47, n. 2, p.263-292, 1979. 
KAZANJIAN, R. Relation of dominant problems to stages of growth in technology-based new ventures. Academy of Management Journal, v. 31, n. 2, p.257-279, 1988.

KEATS, B.; BRACKER, J. Toward a theory of small firm performance : a conceptual model. American Journal of Small Business, v. 12, n. spring, p.41-58, 1988.

KLEPPER, S. Entry, exit, growth, and innovation over the product life cycle. American Economic Review, v. 86, n. 3, p.562-583, 1996.

KLOTZ, A.; HMIELESKI, K.; BRADLEY, B.; BUSENITZ, L. New Venture Teams: A Review of the Literature and Roadmap for Future Research. Journal of Management, v. 40, n. 1, p.226$255,2014$.

KNIGHT, F. Risk and Uncertainty. New York: Houghton-Mifflin, 1921.

LEVITT, B.; MARCH, J. Organizational learning. Annual Review of Sociology, v.14, p.319$340,1988$.

LUMPKIN, G.; DESS, G. Clarifying the Entrepreneurial Orientation Construct and Linking It to Performance. The Academy of Management Review, v. 21, n. 1, p.135-172, 1996.

LUMPKIN, G.; DESS, G. Linking two dimensions of entrepreneurial orientation to firm performance: The moderating role of environment and industry life cycle. Journal of Business Venturing, v. 16, n. 5, p.429-451, 2001.

MACMILLAN, I.; SIEGEL, R.; NARASIMHA, P. Criteria used by venture capitalists to evaluate new venture proposals. Journal of Business Venturing, v.1, n. 1, p. 119-128, 1985. MARCH, J. Exploration and exploitation in organizational learning. Organization Science, v.2, n. 1, p. 71-87, 1991.

MATA, J.; PORTUGAL, P.; GUIMARAES, P. The survival of new plants: start-up conditions and post-entry evolution. International Journal of Industrial Organization, v. 13, n. 4, p. 459481,1995

MCCAIN, K. Cocited author mapping as a valid representation of intellectual structure. Journal of the American Society for Information Science, v. 37, n. 3, p. 111-122, 1986.

MCCAIN, K. Mappping authors in intellectual space: A technical overview. Journal of the American Society for Information Science, v. 41, n. 6, p. 433-443, 1990.

MCGRATH, R. Falling Forward: Real Options Reasoning and Entrepreneurial Failure.

Academy of Management Review, v. 24, n. 1, p. 13-30, 1999.

MELLAHI, K.; WILKINSON, A. Organizational failure: a critique of recent research and a 
proposed integrative framework. International Journal of Management Reviews, v. 5/6, n. 1, p. 21-41, 2004.

MILLER, D. The correlates of entrepreneurship in three types of firms. Management Science, v. 29, n. 7, p. 770-793, 1983.

MORENO, A.; CASILLAS, J. Entrepreneurial orientation and growth of SMEs: A causal model. Entrepreneurship: Theory and Practice, v. 32, n. 3, p. 507-528, 2008.

NELSON, R.; WINTER, S. An Evolutionary Theory of Economic Change. Cambridge, MA: The Belknap Press, 1982.

NERUR, S.; RASHEED, A.; NATARAJAN, V. The intellectual structure of the strategic management field: An author co-citation analysis. Strategic Management Journal, v. 29, n. 3, p.319-336, 2008.

PARÉ, G.; TRUDEL, M.; JAANA, M.; KITSIOUS, S. Synthesizing information systems knowledge: a typology of literature reviews. Information \& Management, v.52, n. 2, p.183-199, 2015.

PEARCE, J.; ROBBINS, K. Toward improved theory and research on business turnaround. Journal of Management, v. 19, n. 3, p. 613-636, 1993.

PENROSE, E. The Theory of the Growth of the Firm. White Plains, NY: M.E. Sharpe, 1959. PFEFFER, J.; SALANCICK, G. The External Control of Organizations: A Resource Dependence Perspective. New York: Harper Row, 1978.

PFEFFER, J.; SUTTON, R. Evidence-based management. Harvard Business Review, p. 62-74, 2006.

PILKINGTON, A. Bibexcel - Quick Start Guide to Bibliometrics and Citation Analysis, 2006.

PODSAKOFF, P.; MACKENZIE, S.; LEE, J.; PODSAKOFF, N. Common method biases in behavioral research: a critical review of the literature and recommended remedies. The Journal of Applied Psychology, v. 88, n. 5, p. 879-903, 2003.

PORTER, M. Competitive Advantage. New York: Free Press, 1985.

RAMOS-RODRÍGUEZ, A.; RUÍZ-NAVARRO, J. Changes in the intellectual structure of strategic management research: a bibliometric study of theStrategic Management Journal, 19802000. Strategic Management Journal, v. 25, n. 10, p. 981-1004, 2004.

SCHULZE, W.; LUBATKIN, M.; DINO, R.; BUCHHOLTZ, A. Agency relationships in family 
firms: theory and evidence. Organization Science, v. 12, n. 2, p. 99-116, 2001.

SCHUMPETER, J. The theory of economic development: an inquiry into profits, capital, credit, interest, and the business cycle. Harvard Economic Studies, v. 46. London: Transaction Books, 1934.

SERRA, F.; FERREIRA, M.; ALMEIDA, M. Organizational decline: a yet largely neglected topic in organizational studies. Management Research: The Journal of the Iberoamerican Academy of Management, v. 11, n. 2, p. 133-156, 2013.

SHAFIQUE, M. Thinking inside the box? Intellectual structure of the knowledge base of innovation research (1988-2008). Strategic Management Journal, v. 34, n.1, p. 62-93, 2013. SHANE, S.; STUART, T. Organizational Endowments and the Performance of University Startups. Management Science, v. 48, n. 1, p. 154-170, 2002.

SHANE, S.; VENKATARAMAN, S. The promise of entrepreneurship as a field of research. Academy of Management Review, v. 25, n. 1, p. 217-227, 2000.

SHARMA, P. An overview of the field of family business studies: current status and directions for the future. Family Business Review, v. 17, n. 1, p. 1-36, 2004.

SHEPHERD, D. Learning from business failure: propositions of grief recovery for the selfemployed. Academy of Management Review, v. 28, n. 2, p. 318-328, 2003.

SINGH, J. V.; TUCKER, D. J.; HOUSE, R. J. Organizational Legitimacy and the Liability of Newness. Administrative Science Quarterly, v. 31, p. 171-193, 1986.

SITKIN, S. Learning through failure: The strategy of small losses. Research in Organizational Behavior, v. 14, p. 231-266, 1992.

SMALL, H.; Garfield, E. Co-citation analysis of science : henry small on mapping the collective mind of science. Current Comments, v. 19, p. 3-13, 1993.

STAW, B. M.; SANDELANDS, L. E.; DUTTON, J. E. Threat-Rigidity Effects in Organizational Behavior: A Multilevel Analysis Barry M. Staw , Lance E . Administrative Science Quarterly, v. 26, n. 4, p. 501-524, 1981.

STINCHCOMBE, A. L. Social Structure and Organizations. In J. Marsh (Ed.), Handbook of Organizations, 1965.

STUART, T., HOANG, H., HYBELS, R. Interorganizational endorsements and the performance of entrepreneurial ventures. Administrative Science Quarterly, v. 44, n.2, p. 315-349, 1999. SUBRAMANYAM, K. Bibliometric studies of research collaboration: a review. Journal of 
Information Science, v. 6, n. 1, p. 33-38, 1983.

TEECE, D. Profiting from technological innovation: Implications for integration, collaboration, licensing and public policy. Research Policy, v. 15, n. February, p. 285-305, 1986.

TIMMONS, J. New Venture Creation: Entrepreneurship for the 21st Century. New York: McGraw-Hill, Inc, 1994.

TORNIKOSKI, E.; NEWBERT, S. Exploring the determinants of organizational emergence: A legitimacy perspective. Journal of Business Venturing, v. 22, n.2, p. 311-335, 2007.

TORRES, A.; SERRA, F.; ALMEIDA, M.; FERREIRA, M. O declínio de uma empresa brasileira de grande porte: o caso Gradiente. BASE - Revista de Administração E

Contabilidade Da Unisinos, v. 10, n. 3, p. 273-292, 2013.

TOWNSEND, D.; BUSENITZ, L. Turning water into wine? Exploring the role of dynamic capabilities in early-stage capitalization processes. Journal of Business Venturing, v. 30, n. 2, p. 292-306, 2015.

TOWNSEND, D.; BUSENITZ, L.; ARTHURS, J. To start or not to start: Outcome and ability expectations in the decision to start a new venture. Journal of Business Venturing, v. 25, n.2, p. 192-202, 2010.

TRAHMS, C.; NDOFOR, H.; SIRMON, D. (2013). Organizational Decline and Turnaround: A Review and Agenda for Future Research. Journal of Management, v. 39, n. 5, p. 1277-1307, 2013.

TUMA, N.; HANNAN, M. Social Dynamics Models and Methods. Cloth: Academic Press, 1984.

TUSHMAN, M. L.; ROMANELLI, E. Organizational evolution: a metamorphosis model of convergence and reorientation. Research in Organizational Behavior, v. 7, p. 171-223, 1985. UCBASARAN, D.; WESTHEAD, P.; WRIGHT, M. Discussion Papers on Entrepreneurship , Growth and Public Policy, 2009.

VERHEES, F.; MEULENBERG, M. Market Orientation, Innovativeness, Product Innovation, and Performance in Small Firms. Journal of Small Business Management, v. 42, n. 2, p. 134$154,2004$.

WAGNER, J. The post-entry performance of new small firms in German manufactoring industries. Journal of Industrial Economics, v. 42, n. june, p. 141-154, 1994.

WEITZEL, W.; JONSSON, E. Decline in organizations : a literature integration and extension. 
Administrative Science Quarterly, v. 34, p. 91-109, 1989.

WESTHEAD, P.; WRIGHT, M. Novice, portfolio, and serial founders: are they different?

Journal of Business Venturing, v. 13, n. 3, p. 173-204, 1998.

WHETTEN, D. Sources, responses and effects of organizational decline. In J. Kimberly R.

Miles (Eds.), The Organizational Life Cycle, v. 37, p. 342-374. San Francisco: Jossey-Bass, 1980.

WHETTEN, D. Organizational growth and decline processes. Annual Review of Sociology, v. 13, p. 335-358, 1987. 